\title{
Isenção e autonomia na perícia médica previdenciária no Brasil
}

Michelle Larissa Zini Lise ${ }^{1}$, Sami Abder Rahim Jbara El Jundi ${ }^{2}$, Jorge Utaliz Guimarães Silveira ${ }^{3}$, Renata Souza Coelho ${ }^{4}$, Lisiane Maiser Ziulkoski ${ }^{5}$

\section{Resumo}

A perícia médica é requisito obrigatório para a concessão da maioria dos benefícios concedidos pelo Instituto Nacional do Seguro Social. Trata-se de atividade complexa, pois exige amplos conhecimentos de medicina e de legislação, e que tem por finalidade garantir a subsistência do trabalhador segurado quando incapacitado. Verificou-se que diversos são os elementos passíveis de modificação e que beneficiariam o atuar do perito. A adequação do ambiente físico, o esclarecimento da população acerca das particularidades da atividade pericial, o fim da obrigatoriedade da entrega da Comunicação de Resultado de Requerimento pelo médico, a melhora do sistema informatizado disponibilizado, a discussão acerca do número de atividades agendadas por dia que respeite a capacidade do perito, afastando-o da exaustão e, portanto, dos erros, bem como o respeito às normas balizadoras da atividade médica emanadas dos conselhos de medicina, permitiriam o labor com a isenção e a autonomia necessárias.

Palavras-chave: Autonomia médica. Perícia. Ética.

\section{Resumen}

Imparcialidad y autonomía en el examen médico de la seguridad social en Brasil

El examen médico es requisito obligatorio para la concesión de la mayor parte de los beneficios otorgados por el Instituto Nacional de la Seguridad Social. Se trata de una actividad compleja que requiere un amplio conocimiento de la medicina y la ley, y tiene como objetivo garantizar la subsistencia del trabajador asegurado cuando incapacitado. Se comprobó que muchos elementos son modificables y que beneficiarían la labor del experto. La adecuación del entorno físico, la clarificación de la población acerca de las particularidades de la actividad pericial, el fin de la obligación del médico perito entregar la Comunicación de Resultado de Requerimiento, la mejora del sistema informático disponible, la discusión sobre el número de actividades programadas por día que respete la capacidad del experto, alejándole del agotamiento y como consecuencia de posibles errores en sus evaluaciones, así como el respeto a las normas delimitadoras de la actividad médica emitidas por los consejos médicos, permitiría la labor con la imparcialidad y la autonomía necesarias.

Palabras-clave: Autonomía médica. Peritaje. Ética.

\section{Abstract}

\section{Disclaimer and autonomy in medical expertise social security in Brazil}

The medical examination is a mandatory requirement for the granting of most of the benefits granted by the National Social Security Institute. It is a complex activity that requires extensive knowledge of medicine and law and aims to ensure the maintenance of the insured worker when incapacitated.

It was found that several elements are modifiable and which would benefit the work of the expert. The adequacy of the physical environment, clarification of the population about the particularities of expert activity, the end of the obligation by the physician to deliver the Communication of Results, the improvement of the computerized system available, the discussion about the number of scheduled activities per day that respects the ability of the expert, away from the exhaust and thus the errors, as well as respect for the rules that guide the best medical practice issued by the medical council, would allow the work to the exemption and the necessary autonomy.

Key words: Medical autonomy. Expertise. Ethics.

1. Doutoranda dramizini@yahoo.com.br PUC/RS 2. Mestre samieljundi@risk-0.com UFRGS/RS 3. Especialista jorge@traumato. com.br 4. Especialista renatacoelho@uol.com.br 5. Especialista lisimz@terra.com.br - Instituto Nacional de Seguridade Social, Porto Alegre/RS, Brasil.

Correspondência

Michelle Lise - Mãe de Deus Center - Av. Soledade, 569, sala 912 Torre Alfa CEP 90470-340. Porto Alegre/RS, Brasil.

Declaram não haver conflito de interesse. 
A Previdência Social é a maior e mais antiga seguradora do trabalhador brasileiro, bem como a maior distribuidora de renda do país. Sua história remonta a 1888, com o Decreto 9.912-A que regulou o direito à aposentadoria dos empregados dos Correios e fixou em 30 anos de efetivo serviço e idade mínima de 60 anos os requisitos para obter o benefício ${ }^{1}$. Ao longo dos anos a Previdência Social brasileira passou por várias mudanças conceituais e estruturais, envolvendo abrangência, graus de coberturas, elenco de benefícios oferecidos e forma de financiamento do sistema ${ }^{2}$. Na Constituição de $1988^{3}$ a Previdência Social é expressamente afirmada como direito social (art. $6^{\circ}$ ) e, ao lado do direito à saúde e à assistência social, se apresenta como espécie do gênero seguridade social, explicitado no art. 194 da carta constitucional.

A Previdência é definida como o seguro social para a pessoa que contribui, sendo uma instituição pública que tem por objetivo reconhecer e conceder direitos aos seus segurados. O Instituto Nacional do Seguro Social (INSS) é uma autarquia federal, vinculada ao Ministério da Previdência Social, que tem por finalidade promover o reconhecimento de direito ao recebimento de benefícios por ela administrados ${ }^{1}$.

Os contribuintes da Previdência Social estão submetidos ao Regime Geral de Previdência Social (RGPS) instituído pela Lei 8.212/91 ${ }^{4}$. Trata-se de regime de filiação obrigatória, conforme a redação do art. 201 da Emenda Constitucional (EC) 20 de $1998^{5}$. Assim, os benefícios previdenciários são custeados por todos os trabalhadores contribuintes, independente de receberem ou não benefício em algum momento da vida.

A lei é impositiva ao estabelecer o direito do segurado (o auxílio será devido), quando satisfeitos os requisitos legais. Dentre estes, entendeu o Estado por estabelecer, por meio do Decreto 3.048/99 ${ }^{6}$, a necessidade de perícia médica realizada pela autarquia previdenciária. O laudo pericial é a designação da peça médico-legal escrita pelo perito, na qual relata a perícia.

A verificação do direito a recebimento dos benefícios previdenciários passa, então, em muitos casos, pela ação da perícia médica, ou seja, o indivíduo pleiteante deve ser examinado por médico perito designado pelo INSS, para determinar a existência ou não de condição que indique a necessidade e enquadramento no direito de receber o benefício pleiteado. Ao perito previdenciário são definidos quesitos para avaliação pericial: diagnóstico nosológico, conforme a Classificação Internacional de Doenças (CID); determinação da data de início da doença; data de início da incapacidade; condição de segurado; isenção de carência, de imposto de renda, de existência ou não de incapacidade, de nexo técnico e nexo técnico epidemiológico previdenciário (NTEP); estimativa de cessação e possibilidade de recuperação (prognóstico); emissão e entrega do resultado e, ainda, coleta de ciência do resultado pelo examinado, para fins legais.

Dentre os benefícios que podem ser requeridos pelos trabalhadores salienta-se o auxílio-doença, explicitado nos artigos 59 a 63 da Lei 8.213/91 ${ }^{7}$. O auxílio-doença se caracteriza por ser um benefício previdenciário de curta duração e renovável a cada oportunidade em que o segurado dele necessite. É um benefício pago em decorrência de incapacidade temporária ${ }^{8}$ e não da mera existência de doença.

Quer tenha inserção judicial ou administrativa, a perícia médica é uma ferramenta da medicina legal. Os diversos tipos de perícia devem ser entendidos como áreas de atuação da medicina legal, especialidade mater à qual todas se vinculam ${ }^{9}$. Recentemente, o Brasil reconheceu como nova e única especialidade a Medicina Legal e Perícia Médica, conforme a Resolução 1.973/11 do Conselho Federal de Medicina (CFM) ${ }^{10}$.

Contudo, a perícia previdenciária é algo diversa das demais. É uma perícia administrativa que tem por finalidade avaliar, entre outras coisas, a existência de incapacidade laboral temporária ou permanente do pleiteante, com o objetivo de consubstanciar a concessão de benefício junto ao INSS. Nesse caso, a ação pericial tem caráter judicante, haja vista que emite juízo de valor acerca dos elementos obtidos na perícia e não somente os relata. Assim, a perícia previdenciária se afasta do adágio visum et repertum, expressão antiga que se tornou lema dos profissionais peritos e que significa ver bem (examinar minuciosamente) e referir (descrever, documentar) exatamente o que viu ${ }^{11}$.

Embora o benefício prevalente no dia a dia das avaliações periciais seja chamado de auxílio-doença, não é esse o bem jurídico que está segurado pelo INSS, mas sim a capacidade laboral ${ }^{9}$. Esse equívoco da nomenclatura atua como fator gerador de confusão ao requerente, ao dar a ideia de que bastaria haver uma doença para ser concedido o benefício.

As avaliações médico-periciais no INSS não buscam fazer o diagnóstico de uma doença, mas sim avaliar a repercussão do agravo sobre a capacidade laborativa dos requerentes. Essas perícias levam em consideração a existência da incapacidade laboral gerada pelo agravo, que deve ser de- 
vidamente informado pelo requerente, mediante documentação fornecida pelo mesmo comprovando tal patologia e que inclua, por exemplo, dentre outros, apresentação do atestado do seu médico assistente, bem como o resultado de exames complementares. A falta de comprovantes de tratamento pode ocasionar a não concessão do benefício, com base no art. 77 do Decreto 3.048/99 ${ }^{6}$. A falta confessa de tratamento é motivo suficiente para a negativa de benefício em face da exigência legal ${ }^{2}$.

\section{Questões éticas}

A perícia médica não pode ser confundida com a medicina assistencial. A relação entre médico e periciado é completamente diferente da relação médico-paciente. Esta se fundamenta na confiança mútua, na empatia, na busca do diagnóstico, do tratamento, do alívio. Por sua vez, a relação médico-pericial fundamenta-se na desconfiança mútua, no compromisso com a verdade, com o parecer objetivo. A diferença é tão relevante que o Código de Ética Médica (CEM) ${ }^{12}$ tem um capítulo especificamente dedicado ao tema ${ }^{9}$. Como ressalta o Capítulo XI do CEM (Auditoria e Perícia Médica), é vedado ao médico:

Art. 93. Ser perito ou auditor do próprio paciente, de pessoa de sua família ou de qualquer outra com a qual tenha relações capazes de influir em seu trabalho ou de empresa em que atue ou tenha atuado. Art. 98. Deixar de atuar com absoluta isenção quando designado para servir como perito ou como auditor, bem como ultrapassar os limites de suas atribuições e competência ${ }^{12}$.

Acerca do sigilo médico, a perícia também difere da medicina assistencial, como cita Fraraccio em sua obra Medicina forense contemporânea: En efecto, se hay acto médico totalmente desprovisto de la obligatoriedad de guardar secreto profesional, es el peritaje médico-legal. Esto debe ser así porque generalmente el paciente no solicita la actuación del médico (no se establece una relación contractual con el profesional) dado que el peritaje es solicitado por la autoridad ${ }^{13}$.

\section{A autonomia do perito do INSS}

A atenta análise da atividade médica pericial previdenciária no país revela diversos fatores que afetam em maior ou menor grau a autonomia do perito do INSS, tais como: 1) limitações quanto a confecção do laudo médico pericial; 2) limitação temporal; 3) falta de área exclusiva para a perícia; 4) relação de subordinação ao INSS e; 5) falta de aparelhamento institucional. Cumpre salientar, todavia, que além dos aspectos discutidos pontualmente a seguir há diversos outros que também merecem mais atenção para serem identificados e corrigidos, a fim de melhorar e profissionalizar a atividade pericial previdenciária em nosso país.

\section{Limitações quanto à confecção do laudo médico pericial}

As limitações quanto à confecção do laudo médico pericial ocorrem mediante a obrigatoriedade do uso de um aplicativo de informática, o Sistema Administrativo de Benefícios por Incapacidade (Sabi). o Sabi consiste em um sistema informatizado que analisa previamente as variáveis administrativas, como qualidade de segurado, períodos de carência e outras, permitindo que ao final do lançamento dos dados do exame pericial as conclusões sejam codificadas e transmitidas para computadores centrais, para processamento do benefício e geração de numerários a serem pagos aos segurados na rede bancária ${ }^{2}$.

O Sabi apresenta diversos fatores que circunscrevem a autonomia do perito. Dentre eles, limita o número de caracteres que podem ser digitados em cada campo e impossibilita a anexação de documentos, restando aos peritos digitar todos os elementos relevantes apresentados pelo requerente. Atualmente, o laudo deve estar restrito ao espaço de uma página - muitas vezes, os laudos periciais tornam-se exíguos de informação, sendo posteriormente questionados quanto à qualidade.

O Sabi também conclui por negativa automática do benefício para determinados CID, ou seja, em se utilizando determinado CID haverá negativa automática do pedido de benefício, independente do que seja descrito ou concluído pelo perito em seu laudo. Adicionalmente, não reconhece diversos CID elencados na classificação atual, tornando necessária a troca do CID mais adequado por outro que exista no sistema.

\section{Limitação temporal}

A limitação temporal determinada pela instituição para a realização do exame pericial relacionase ao cumprimento de uma agenda pré-marcada com 18 a 24 perícias/dia/perito. Assim, as tarefas de fazer a identificação do periciado, levantar sua histó- 
ria, realizar o exame físico, analisar a documentação e os quesitos postulados pelo questionário, formular as respostas, consultar a bibliografia, emitir o parecer e digitá-lo no Sabi ficam comprimidas em apenas 20 minutos, prazo final para a entrega imediata do resultado. Obviamente, tal determinação torna impossível a realização do ato médico-legal com a necessária tranquilidade, tendo como consequências a confecção de laudos mais frágeis e a sensação de urgência para o médico. Uma atividade que devido à própria natureza complexa e a inafastável importância derivada de seu resultado, qual seja, a subsistência do trabalhador por um período de incapacidade, deveria ter condições de ser levada a cabo com o máximo de cuidado e serenidade pelo perito.

\section{Falta de área exclusiva para a perícia}

A falta de área destinada exclusivamente à perícia, fisicamente separada da sala de espera dos segurados, pode ser considerada uma realidade crônica. Na maioria das agências, o total acesso de qualquer indivíduo, a qualquer tempo, às salas de exame médico expõe o perito a frequentes interrupções de sua atividade e, mesmo, a situações de possível agressão pelos requerentes insatisfeitos. Tal fato faz com que se criem, durante a jornada de trabalho, um clima de vulnerabilidade e insegurança constantes, que prejudica o desempenho dos peritos, haja vista que os médicos evitam sair das salas para discutir casos em que há dúvidas, o que seria extremamente salutar ao trabalho pericial.

\section{Relação de subordinação ao INSS}

A relação de subordinação ao INSS fica evidente quando se pensa que o perito é remunerado pela instituição, para a qual presta o serviço. Trata-se de aspecto relevante e ainda ignorado pelo INSS. Em razão do vínculo empregatício com o INSS de uma das partes em lide, instaura-se precedente que permite que se possa questionar a isenção do laudo pericial ${ }^{9}$. Abre-se espaço para um possível conflito de interesses quando a instituição que paga os benefícios é a mesma que contrata e estabelece as normas para o trabalho do perito que subsidiará a concessão ou não do benefício. Desta forma, há a sujeição física e administrativa do ato médico ao controle das chefias e normas administrativas, o que pode ser fonte de falta de isenção no ato pericial.

\section{Falta de aparelhamento institucional \\ Dadas as condições acima explicitadas, espe- cialmente as concernentes a tempo e espaço, esta-}

belece-se um agravante no grau de dificuldade que o perito encontra para estabelecer o laudo pericial. Trata-se da falta de aparelhamento institucional que inibe a consulta a pareceres de outros médicos ou a solicitação de exames, em casos mais complexos, embora isso esteja previsto no Manual do perito médico, versão 2, 4.3, item c: requisitar, quando necessário, exames complementares e pareceres especializados ${ }^{14}$.

Ante tais condições adversas ao bom andamento da atividade pericial e considerando, ainda, a importância desta na concessão de benefícios ao trabalhador, cabe discutir o modelo atual a partir do ordenamento normativo da atividade.

\section{Discussão}

Acerca dos tópicos anteriormente identificados, o Conselho Regional de Medicina do Estado do Rio Grande do Sul (Cremers) pronunciou-se em parecer de 2010:

1. O exame médico-pericial no âmbito da Previdência Social tem por objetivo emitir um laudo técnico (parecer) que servirá para embasar ou não a decisão final de concessão de benefício:

a. Portanto, o espaço destinado à elaboração do laudo médico-pericial deve ser ilimitado, permitindo que cada médico exerça este ato de forma autônoma, atendendo seus critérios de qualidade técnica; b. Para melhor qualificar este laudo técnico, vislumbra-se a necessidade da disponibilização de recursos para anexar ao laudo documentos conforme originais apresentados, assim como outros elementos coletados durante o exame (imagens, fotos etc.); c. Além disso, vislumbra-se a necessidade de que seja instituído um modelo de laudo que atenda aos padrões mínimos da documentação médico-legal, assim como permita um adequado preenchimento por parte dos médicos peritos.

5. É necessário que a tabela de códigos usada pelo INSS tenha como base a CID 10 contemplada em sua totalidade, sem limitação dos diagnósticos utilizados para concessão de benefícios ${ }^{15}$.

As características da atividade pericial apontadas pelo Cremers encontram amparo também no Capítulo II do CEM, que define ser direito do médico: VIII - Decidir, em qualquer circunstância, levando em consideração sua experiência e capacidade profissional, o tempo a ser dedicado ao paciente, evitando que o acúmulo de encargos ou de consultas venha a prejudicá-lo ${ }^{12}$. Fica claro, por conseguinte, 
que o CEM assegura ao médico a autonomia para estabelecer o tempo necessário para a realização dos respectivos atos médicos, incluindo-se nestes o ato médico pericial.

Ainda a respeito do tempo que o médico pode ter para realizar sua atividade, quer consulta, exame ou perícia, diversas indagações foram feitas por médicos peritos de diversos estados do Brasil aos CRM e, inclusive, à Organização Mundial da Saúde (OMS). As respostas são taxativas ao assinalar que não há que se falar em tempo mínimo, médio ou máximo para o ato médico. De fato, a OMS posicionou-se de forma inequívoca em e-mail assinado eletronicamente pela dra. Rachel Pedersen (Assistant, Disability and Rehabilitation (DAR), Department of Violence and Injury Prevention and Disability, Noncommunicable Diseases and Mental Health, World Health Organization): The evaluation time are also dependent on the condition and treating phisician, I am afraid there are no specific recommendations on this. Esta mesma autoridade já se pronunciara em comunicação anterior informando que a OMS não propõe recomendações para tempo de tratamento em face da peculiaridade de cada caso.

O item quatro do parecer da Câmara Técnica de Perícias (PG 09-036/09) define: O médico na função de perito não deve aceitar qualquer tipo de constrangimento ou restrição que possa influir no desempenho de sua atividade, que deve ser realizada com absoluta isenção, imparcialidade e autonomia, razão pela qual não deve ser estabelecido um tempo fixo para a realização do ato médico-pericial ${ }^{15}$. No mesmo sentido, o processo-consulta ao Conselho Regional de Medicina do Estado do Paraná a respeito das perícias médicas emitiu parecer esclarecendo: Note-se que nenhum trabalhador deve permanecer envolvido em atividades de alta exigência durante todo o tempo de sua jornada, especialmente em tarefas de alta demanda cognitiva, como são as perícias e consultas médicas, sob risco de fadiga intensa e, consequentemente, o aumento da chance de erros ${ }^{16}$.

A partir da resposta dos questionamentos feitos aos CRM e da breve descrição da atividade dos peritos médicos no âmbito do INSS, fica evidente que, como consequência dos fatores acima relacionados, não são providas as condições ideais (e sequer adequadas) de trabalho, as quais deveriam contemplar a autonomia e primar pela isenção. 0 que se pode depreender do conjunto de problemas assinalados é que em decorrência destas condições adversas não apenas os médicos peritos se veem prejudicados, mas estas circunstâncias atingem, especialmente, a população que precisa deste serviço e, por determinação legal, não pode recorrer a outra instância para obtê-lo.

Além dos aspectos da atividade médico-pericial acima discutidos, a situação do profissional é ainda agravada pela obrigatoriedade, imposta por ato infraconstitucional, de entrega da Comunicação de Resultado de Requerimento (Crer) imediatamente após a realização do ato pericial. A Crer é o documento que contém o resultado conclusivo do INSS após a análise de todos os dados de um determinado pedido, ou seja, não é o laudo pericial confeccionado pelo perito, mas sim o resultado final do somatório dos dados periciais e administrativos do requerente.

Impor ao médico que realize uma ação de cunho administrativo, que caberia à instituição, e ainda obrigá-lo a solicitar a assinatura do recebedor do documento em momento imediatamente posterior à realização da perícia termina por personificar o perito como o único responsável pela decisão institucional, o que traz como consequência outro fator que pode comprometer a isenção da conclusão pericial: o médico pode temer por sua integridade ao entregar um resultado que negue a concessão do benefício pleiteado.

Desta forma, por óbvio, em não tendo seu pleito atendido, é normal haver algum grau de contrariedade do requerente para com o resultado. Assim, o requerente pessoaliza o resultado, tomando o perito que o atendeu como o único responsável por seu infortúnio. Cabe salientar, ainda, que muitas vezes, mesmo constatada e registrada a incapacidade do requerente por parte do médico, pode não haver concessão do benefício, devido a impedimentos de ordem administrativa, tais como falta de período de contribuição necessário, entre outros.

Resta claro que também esta determinação institucional atua como importante fator na geração de conflitos entre peritos e requerentes, propiciando incontáveis situações de hostilidade. Muitas delas culminam em agressão, frequentemente registradas na Polícia Federal por médicos peritos em todo o país, como sinaliza o citado Parecer PG 09036/09 da Câmara Técnica de Perícias ${ }^{15}$. A consequência deste modus operandi da instituição acerca da Crer é o inevitável e constante temor do perito ao perceber o ânimo do requerente, que está em busca de um benefício pecuniário e que vincula seu recebimento exclusivamente ao ato pericial, personificando e pessoalizando o ato. Assim, novamente, os laudos e seus resultados podem sofrer influência marcada da estrutura elaborada pela instituição, podendo comprometer a isenção pericial e o resultado de seu trabalho. 
Cabe salientar que essa norma interna do INSS foi objeto de questionamento específico junto ao $\mathrm{CRM} / \mathrm{RS}$, que se posicionou claramente no referido Parecer 09-036/09 da Câmara Técnica de Perícias Médicas, afirmando no item 2: Sendo o médico o responsável pela emissão de apenas um parecer técnico, não cabe a este profissional entregar ao segurado o resultado final do requerimento do benefício, o que, além de ser um fato potencialmente gerador de conflito, tem sido causa de constantes agressões (inclusive com ameaça à vida dos médicos) ${ }^{15}$. Embora seja ponto pacífico para o Conselho, que rege a atividade médica no estado, bem como para todos os peritos, a posição da autarquia ainda permanece, mantendo a determinação de serem os médicos os responsáveis por entregar a Crer aos requerentes, em todo o país.

Ainda, na contramão dos ditames éticos da profissão e com aparente desconhecimento da gravidade das consequências da exigência da entrega da Crer pelo médico imediatamente após a realização da perícia, está o Projeto de Lei (PL) 7.209/10 ${ }^{17}$, que pretende incluir o seguinte parágrafo: $\S 3^{\circ} \mathrm{A}$ conclusão pela incapacidade ou não deverá ser comunicada ao segurado por escrito pela perícia médica, ao término do procedimento pericial.

Convenhamos, se a entrega da Crer pelo médico é fator gerador de conflito, como exposto anteriormente, e considerando que a tomada de decisão e a confecção do laudo pericial apresentam diversas etapas, que não necessariamente estarão concluídas ao fim do exame clínico em si e, principalmente, que o laudo pericial e a Crer são de acesso amplamente franqueado ao requerente logo que concluídos todos os atos administrativos envolvidos e a partir do momento em que este os solicite ao INSS, não há como justificar a inclusão do parágrafo no PL proposto.

Senão vejamos, na esfera criminal o Código de Processo Penal (CPP) define o prazo para confecção e entrega do laudo em 10 dias, prorrogáveis se necessário a pedido do perito: Capítulo II, do Exame do Corpo de Delito, e das Perícias em Geral:

Art. 160. Os peritos elaborarão o laudo pericial, onde descreverão minuciosamente o que examinarem, e responderão aos quesitos formulados. (Redação dada pela Lei 8.862, de 28.3.1994)

Parágrafo único. O laudo pericial será elaborado no prazo máximo de 10 dias, podendo este prazo ser prorrogado, em casos excepcionais, a requerimento dos peritos. (Redação dada pela Lei 8.862, de 28.3.1994) ${ }^{18}$
Na esfera civil, de acordo com o Código de Processo Civil (CPC), o laudo poderá ser entregue em até 20 dias antes da audiência marcada ${ }^{19}$. Comparando o prazo disponível para confecção e entrega de laudos nas esferas civil e criminal, parece completamente desproporcional que para a entrega do laudo pericial no âmbito previdenciário/administrativo haja tamanha urgência que necessite sua conclusão e entrega imediatamente após o ato médico.

\section{Alternativa ao modelo atual}

Em 2001, Portugal implantou um modelo independente, autônomo, oficial e autossustentável de medicina legal. Esse modelo foi aprovado pela Comunidade Europeia e posteriormente adotado pelos Estados-membros. A Austrália não só adotou o modelo português, como o aperfeiçoou. $O$ modelo concentra a gestão de todos os institutos médicolegais (IML) em um único órgão, o Instituto Nacional de Medicina Legal (INML). Este órgão é vinculado ao Ministério da Justiça português, que indica o seu presidente dentre os legistas que o integram ${ }^{9}$.

Compete ao INML definir a política nacional nas áreas de medicina legal e outras ciências forenses, prestar suporte técnico e laboratorial necessários aos tribunais, gerir e controlar a qualidade dos serviços vinculados - emitindo diretivas técnicocientíficas que promovam a harmonização de metodologias, técnicas e laudos periciais. A essa instituição compete cuidar da formação, qualificação e avaliação dos recursos humanos necessários ${ }^{9}$.

Do ponto de vista organizacional, o INML tem total autonomia técnica e administrativa, cabendo exclusivamente ao órgão designar os profissionais para cada atividade. O INML presta serviços não apenas ao Judiciário, mas a qualquer entidade pública ou privada que requeira conhecimentos médico-legais e de ciências forenses, recebendo a contrapartida de remuneração tabelada e divulgada no Diário Oficial, organizada por procedimentos. A total autonomia do órgão, inclusive financeira, garante a isenção aos procedimentos realizados, qualidade indispensável em atos de natureza médico-legal ${ }^{9}$.

\section{Considerações finais}

A perícia médica previdenciária é requisito obrigatório para a atribuição da maioria dos benefícios concedidos pelo INSS, sendo, pois, inafastável 
pilar na proteção do trabalhador quando este se encontra impossibilitado de prover sua subsistência por meio de sua atividade. Este tipo de atividade exige conhecimentos amplos tanto de medicina quanto de legislação, como salientado.

A valorização da perícia e a busca pela solução dos fatores que impedem o melhor desenvolvimento da atividade é de interesse de todos os envolvidos na questão, quais sejam: os médicos que a ela escolheram se dedicar, os segurados da Previdência Social que buscam o atendimento e a sociedade como um todo - que espera a qualificação dos serviços prestados com o erário público.

$\mathrm{O}$ atual modelo de exercício da atividade pericial em prática no INSS cerceia de várias formas o adequado desenvolvimento do trabalho do médico perito, quer por influência da instituição, quer por supressão dos direitos assegurados ao médico e, consequentemente, também àqueles a quem ele atende. É absolutamente desaconselhável ao profissional que se sujeite a uma predeterminação de tempo de duração do exame, bem como ao excesso de atendimentos e tarefas em uma mesma jornada de trabalho. Cabe sublinhar que tal exigência incide em notória infração aos preceitos éticos do CEM, que define os parâmetros da legalidade dos atos médicos no país.

A autonomia no exercício da atividade pericial é essencial para haver qualidade e isenção na elaboração do laudo e respectiva conclusão. Assim, o tempo despendido com cada ato médico deve ser individualizado, bem como a busca da qualidade dos laudos, passando pela possibilidade de discussão de casos complexos, mediante consulta a pesquisas, reuniões técnicas ou acesso a exames especializados, como prevê a Lei da Carreira ${ }^{20}$. Deve ser também estimulada a participação dos peritos em congressos e cursos de formação que contribuirão para sua constante atualização e capacitação, aprimorando o serviço prestado.

Cabe questionar se não seria mais adequada a alocação da perícia médica em órgão independente do pagador dos benefícios, como um novo setor dentro do Ministério da Saúde ou no Ministério da Justiça, como ocorre em Portugal, Austrália e outros países da Comunidade Europeia.

Por fim, é fundamental considerar que as determinações emanadas do CFM devem ser seguidas por todos os médicos do país. Em seu Capítulo II, o atual CEM ${ }^{12}$ cita que é direito do médico: III - Apontar falhas em normas, contratos e práticas internas das instituições em que trabalhe quando as julgar indignas do exercício da profissão ou prejudiciais a si mesmo, ao paciente ou a terceiros, devendo dirigir-se, nesses casos, aos órgãos competentes e, obrigatoriamente, à comissão de ética e ao Conselho Regional de Medicina de sua jurisdição. Nesse sentido, os questionamentos do presente artigo visam promover a reflexão e discussão amplas, entre a classe médica, gestores do sistema previdenciário e legisladores, bem como a sociedade brasileira, acerca das questões expostas, para que a atividade pericial possa efetivamente cumprir a função que lhe é designada e atender aos anseios dos brasileiros por um atendimento de qualidade.

\section{Referências}

1. Brasil. Ministério da Previdência Social. [internet]. Histórico da previdência. [acesso 22 abr. 2010]. Disponível: http://www.mps.gov.br/conteudoDinamico.php?id=443

2. Gonzaga P. Perícia médica da previdência social. $3^{\text {a }}$ ed. São Paulo: LTr; 2004.

3. Brasil. Constituição (1988). Constituição da República Federativa do Brasil. [internet]. [acesso 13 ago. 2011]. Disponível: http://www.planalto.gov.br/ccivil_03/Constituicao/Constituicao.htm

4. Brasil. Lei n ${ }^{\circ} 8.212,24$ de julho de 1991. Dispõe sobre a organização da Seguridade Social, institui Plano de Custeio, e dá outras providências. [internet]. [acesso 10 jul. 2011]. Disponível: http:// www.planalto.gov.br/ccivil_03/leis/l8212cons.htm

5. Brasil. Constituição (1988). Emenda constitucional $n^{\circ} 20$, de 15 de dezembro de 1998 . Modifica o sistema de previdência social, estabelece normas de transição e dá outras providências. [internet]. 1998 [acesso 25 out. 2010]. Disponível: http://www.planalto.gov.br/ccivil_03/Constituicao/ Emendas/Emc/emc20.htm

6. Brasil. Decreto $n^{\circ} 3.048$, de 6 de maio de 1999. Aprova o Regulamento da Previdência Social, e dá outras providências. [internet]. [acesso 25 out. 2010]. Disponível: http://www.planalto.gov.br/ ccivil_03/decreto/d3048compilado.htm

7. Brasil. Lei n 8.213 , de 24 de julho de 1991. Dispõe sobre os planos de benefícios da Previdência Social e dá outras providências. [internet]. [acesso 15 out. 2010]. Disponível: http://www. planalto.gov.br/ccivil_03/leis/L8213cons.htm

8. Martins SP. Direito da seguridade social. 16a ed. São Paulo: Atlas; 2003.

9. Almeida EHR. A perícia médica previdenciária para a concessão de benefícios por incapacidades. [internet]. Brasília: Associação Brasileira de Medicina Legal; 2009 [acesso 10 dez. 2011]. Disponível: 
http://www.abml-medicinalegal.org.br/departamentos/pericia_medica_previdenciaria_ concessao_beneficios.pdf

10. Conselho Federal de Medicina. Resolução $n^{\circ} 1.973$, de 14 de julho de 2011. Dispõe sobre a nova redação do Anexo II da Resolução CFM n 1.845/2008, que celebra o convênio de reconhecimento de especialidades médicas firmado entre o Conselho Federal de Medicina (CFM), a Associação Médica Brasileira (AMB) e a Comissão Nacional de Residência Médica (CNRM). [internet]. 2011 [acesso 12 dez. 2011]. Disponível: http://www.portalmedico.org.br/resolucoes/ CFM/2011/1973 2011.htm

. Carvalho HV, Segre M, Meira AR, Almeida M, Salaru NNR, Munos DR et al. Compêndio de medicina legal. São Paulo: Saraiva; 1992

12. Conselho Federal de Medicina. Resolução $n^{\circ}$ 1.931, de 17 de setembro de 2009. [internet]. Aprova o Código de Ética Médica e revoga a Resolução CFM n ${ }^{1.246 / 1998 . ~[a c e s s o ~} 13$ out. 2010]. Disponível: http://www.portalmedico.org.br/resolucoes/cfm/2009/1931_2009.htm

13. Fraraccio AV. Medicina forense contemporánea. Buenos Aires: Dosyuna Ediciones Argentinas; 2005. p. 28.

14. Brasil. Ministério da Previdência Social. Manual de perícia médica da previdência social. Versão 2. [internet]. [acesso 22 abr. 2010]. Disponível http://www.cpsol.com.br/upload/arquivo_ download/1872/Manual\%20Pericia\%20Medica\%20da\%20Previdencia\%20Social.pdf

15. Conselho Regional de Medicina do Rio Grande do Sul. Parecer no 09-36/2009. Encaminhamento por parte dos médicos peritos do INSS de uma série de problemas para a realização de exames médicos periciais consequentes a modificações no funcionamento ou falta de condições da instituição. [internet]. [acesso 13 out. 2010]. Disponível: http://www.cremers.org.br/template/ buscalegislacaoTextos. . php?id $=232$

16. Conselho Regional de Medicina do Paraná. Parecer CRMPR $n^{\circ} 2.212 / 10$. Agendamento de perícias médicas previdenciárias. [internet]. 2010 [acesso 22 nov. 2010]). Disponível: http://www. portalmedico.org.br/pareceres/CRMPR/pareceres/2010/2212_2010.htm

17. Brasil. Congresso Nacional. Câmara dos Deputados. Projeto de Lei $n^{\circ} 7.209 / 2010$. Acrescenta o art. 59-A à Lei $n^{\circ} 8.213$, de 24 de julho de 1991, para dispor sobre o direito à informação do segurado do Regime Geral de Previdência Social quanto a resultados de exames médico-periciais para concessão de auxílio-doença. [internet]. 2011 [acesso 22 out. 2010]. Disponível: http:// www.camara.gov.br/sileg/Prop_Detalhe.. sp ? id $=474900$

18. Brasil. Decreto-lei $n^{\circ} 3.689$, de 3 de outubro de 1941. Código de Processo Penal. [internet]. [acesso 15 ago. 2010]. Disponível: http://www.planalto.gov.br/ccivil/Decreto-Lei/Deil3689.htm

19. Brasil. Lei $n^{\circ} 5.869$, de 11 de janeiro de 1973. Institui o Código de Processo Civil. [internet]. [acesso 13 ago. 2010]. Disponível: http://www.planalto.gov.br/ccivil_03/leis/L5869.htm

20. Brasil. Lei n 10.876, de 2 de junho de 2004. Cria a Carreira de Perícia Médica da Previdência Social, dispõe sobre a remuneração da Carreira de Supervisor Médico-Pericial do Quadro de Pessoal do Instituto Nacional do Seguro Social - INSS e dá outras providências. [internet]. [acesso $22 \mathrm{abr}$. 2010]). Disponível: http://www.planalto.gov.br/ccivil_03/_ato2004-2006/2004/lei/l10.876.htm

\section{Participação dos autores}

Michelle Larissa Zini Lise - concepção, revisão bibliográfica, análise e interpretação dos dados, redação do artigo e revisão crítica e aprovação da versão a ser publicada. Sami Abder Rahim Jbara El Jundi delineamento, análise e interpretação dos dados, revisão crítica do artigo, aprovação da versão a ser publicada. Jorge Utaliz Guimarães Silveira, Renata Souza Coelho, Lisiane Maiser Ziulkoski: redação do artigo e revisão crítica, aprovação da versão a ser publicada.

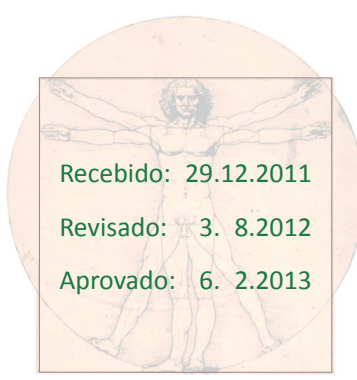

